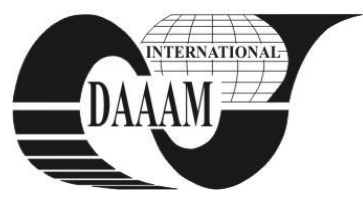

Annals of DAAAM for 2011 \& Proceedings of the 22nd International DAAAM Symposium, Volume 22, No. 1, ISSN 1726-9679 ISBN 978-3-901509-83-4, Editor B. Katalinic, Published by DAAAM International, Vienna, Austria, EU, 2011 Make Harmony between Technology and Nature, and Your Mind will Fly Free as a Bird

\title{
INFLUENCE OF RUNNER SYSTEM DESIGN ON MOLDING PROCESS
}

\author{
KYAS, K[amil]; STANEK, M[ichal]; MANAS, M[iroslav]; MANAS, D[avid]; \\ NAVRATIL, J[an] \& SENKERIK, V[ojtech]
}

\begin{abstract}
Injection molding is one of the most widespread technologies in polymer industry and it becomes more used in rubber industry. This submitted article describes influence of contours of runners on the final properties of the injection molding product. In this research several aspects were changed; two kinds of elastomeric compounds and two different length for narrow and wide runners. Computational analysis shows that changing of the contours of runner changes final properties of product. These received dates should be helpful and advantageous for the polymeric industry, especially rubber industry. These changes of runners can provide business benefits in shortening the product development cycle.
\end{abstract}

Key words: analysis, rubber, injection molding, process

\section{INTRODUCTION}

Injection molding is now a well-established fabrication process in environmental industry. It has more advantages in the most situations over the older processes of compression and transfer molding. These advantages comprise reduced labour cost, better dimensional control and shorter cure times for injection molding process. This process is still improved and other materials (not only thermoplastic) are used for example elastomeric compound. (Kyas et al., 2010)

The injection molding process is a cyclical process, each cycle comprises several operations: feeding, melting and homogenization of polymer grains inside the plasticizing cylinder mold closing, injection under pressure of melt in mold's cavities and cooling or heating of polymer inside the mold, mold opening and ejection of molded piece. In figure 1 there is shown time influence for each parts of cycle. It is necessary to realize, that rubber injection molding cycle is several times longer than for thermoplastics. (Stanek et al., 2006), (Stanek et al., 2009)

During injection molding process, melt is subjected to more severe processing conditions than during compression or transfer molding. Values of temperatures, pressures, and shear stresses are higher, though cure times are shorter in rubber compound. Control over process variables can be more precise.

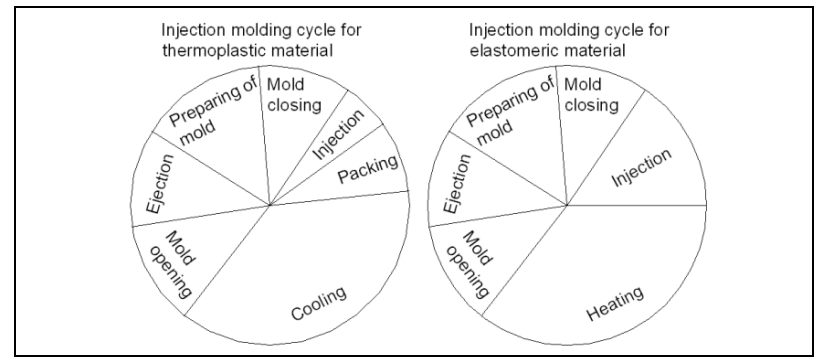

Fig. 1. Injection molding cycle

The cycle time can be minimized by independently controlling barrel temperature, screw speed, mold temperature and injection pressure. That is the reason why the analysis of injection molding process should be improved and understood.
Figure 2. summarizes the concept by illustrating that the elastomeric material, molding method and design of mold cooperate together and these aspects play an interactive role in the molding system.

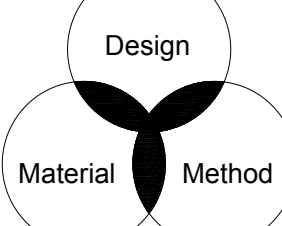

Fig. 2. Role in the molding system

\section{PROCESS SETTINGS}

As it was showed in Fig.2 design, material and method cooperate together in injection molding process. This experiment is focused on improving method by changing design.

\begin{tabular}{|l|c|c|}
\hline \multicolumn{1}{|c|}{ Process parameters } & $\begin{array}{c}\text { EPDM } \\
\text { compound }\end{array}$ & $\begin{array}{c}\text { NBR } \\
\text { compound }\end{array}$ \\
\hline Filling time [s] & 20 & 20 \\
\hline $\begin{array}{l}\text { Pressure controlled - } \\
\text { filling [\%] }\end{array}$ & 99 & 99 \\
\hline Melt (mass) temperature & 100 & 100 \\
\hline $\begin{array}{l}\text { Uniform wall } \\
\text { temperature [C] }\end{array}$ & 170 & 170 \\
\hline Heating [s] & 600 & 600 \\
\hline Post-Curing [s] & 200 & 200 \\
\hline
\end{tabular}

Tab. 1. Process parameters

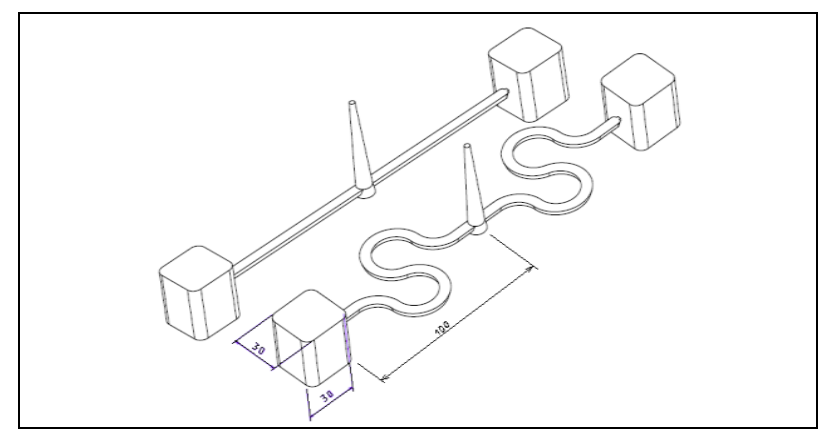

Fig. 3. Type 1- left side, Type 2 - right side

Simulation of injection molding process was analyzed in Cadmould Rubber software. These simulations were optimized to finally form several times. Profitable last setting is shown in Tab 1. As it can be seen amount of each parameters is the same it is very necessary for comparing types of runners. There were two types of runners as it is showed in Fig. 3. Type 1 is linear and type 2 is curved. Mold cavity is a cube with dimension $30 \mathrm{x}$ $30 \times 30 \mathrm{~mm}$. It is prepared for real injection molding process 
for the further research. Two different thicknesses of runners are used for these concrete analyses as it can be seen in Fig. 4.

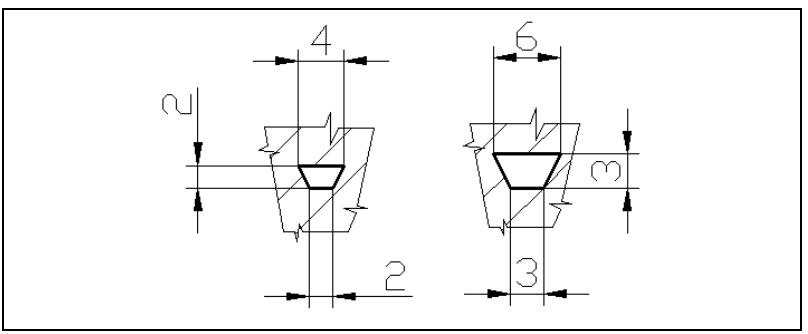

Fig. 4. Section of runners: Narrow- left side, Wide - right side

Temperature and curing closely related together and it is important to know these values during injection molding process of elastomeric compound. Software Cadmould Rubber has great advantage that it can show the temperature and percentage of crossed-links in each moment during injection molding cycle and in the individual layers of the product. It is necessary to consider how many layers use before setting analyse. With large number of layers time of computing increase rapidly on the other hand the results are more accurate.

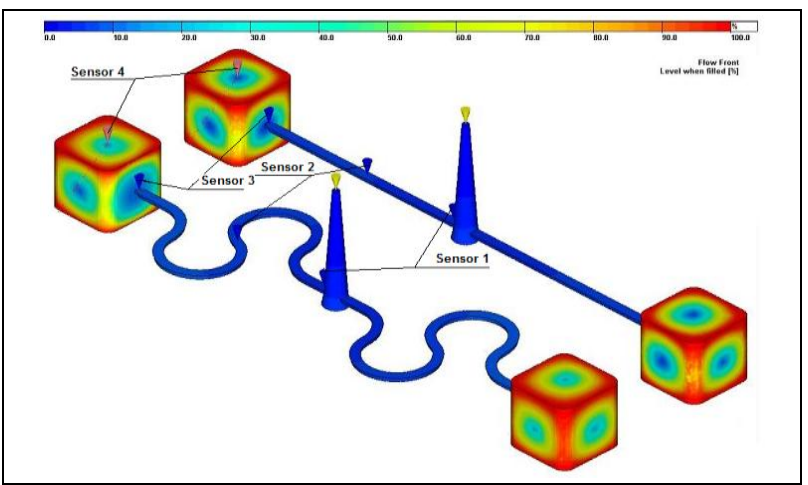

Fig. 5. Using sensors, Sensor1 - Sensor4

In Fig. 5. there is shown result of flow analyse. For the better understanding of injection molding process it is good to know how elastomeric compound behaves in each places of part and sensors are right tools to show behaviour of material. It can rendered results of pressure, temperature, viscosity, shear rate and cure rate which is important for receiving final properties of elastomeric product.

\section{RESULTS AND DISCUSION}

\begin{tabular}{|l|c|c|c|c|c|c|}
\hline $\begin{array}{l}\text { Thickness, } \\
\text { Type }\end{array}$ & $\begin{array}{c}\text { Cure } \\
\text { rate }[\mathrm{s}]\end{array}$ & $\begin{array}{c}\mathrm{T} 1 \\
{\left[{ }^{\circ} \mathrm{C}\right]}\end{array}$ & $\begin{array}{c}\mathrm{T} 2 \\
{\left[{ }^{\circ} \mathrm{C}\right]}\end{array}$ & $\begin{array}{c}\mathrm{T} 3 \\
{\left[{ }^{\circ} \mathrm{C}\right]}\end{array}$ & $\begin{array}{c}\mathrm{T} 4 \\
{\left[{ }^{\circ} \mathrm{C}\right]}\end{array}$ & $\begin{array}{c}\mathrm{P} 1 \\
{[\mathrm{Bar}]}\end{array}$ \\
\hline Narrow, 1 & 633 & 108,7 & 116,4 & 125,4 & 125,8 & 229 \\
\hline Wide, 1 & 641 & 108,7 & 116,7 & 126,8 & 124,7 & 118 \\
\hline Narrow, 2 & 609 & 108,8 & 123,2 & 132,3 & 132,5 & 444 \\
\hline Wide, 2 & 603 & 108,2 & 123,1 & 133,2 & 133,6 & 230 \\
\hline
\end{tabular}

Tab. 2. Measured data for EPDM

In Tab. 2. and Tab. 3. there are results from each sensors. First column is type of geometry, second column shows time when $90 \%$ cure rate is done, from $\mathrm{T} 1$ to $\mathrm{T} 4$ is temperature in sensors and $\mathrm{P} 1$ is pressure which is needed to fill a cavity.

\begin{tabular}{|l|c|c|c|c|c|c|}
\hline $\begin{array}{l}\text { Thickens, } \\
\text { Type }\end{array}$ & $\begin{array}{c}\text { Cure } \\
\text { rate }[\mathrm{s}]\end{array}$ & $\begin{array}{c}\mathrm{T} 1 \\
{\left[{ }^{\circ} \mathrm{C}\right]}\end{array}$ & $\begin{array}{c}\mathrm{T} 2 \\
{\left[{ }^{\circ} \mathrm{C}\right]}\end{array}$ & $\begin{array}{c}\mathrm{T} 3 \\
{\left[{ }^{\circ} \mathrm{C}\right]}\end{array}$ & $\begin{array}{c}\mathrm{T} 4 \\
{\left[{ }^{\circ} \mathrm{C}\right]}\end{array}$ & $\begin{array}{c}\mathrm{P} 1 \\
{[\mathrm{Bar}]}\end{array}$ \\
\hline Narrow, 1 & 343 & 110,1 & 122,2 & 129,7 & 129,9 & 510 \\
\hline Wide, 1 & 352 & 109,9 & 119,9 & 129,1 & 129,6 & 252 \\
\hline Narrow, 2 & 319 & 110,1 & 127,3 & 137,6 & 137,6 & 1007 \\
\hline Wide, 2 & 314 & 109,9 & 127,4 & 137,6 & 137,6 & 510 \\
\hline
\end{tabular}

Tab. 3. Measured data for NBR
As it can be seen difference between thicknesses doesn't change finally properties sharply. On the other hand change of length of runners shorts time which is needed to $90 \%$ of cure rate sometimes more than half minute as it can be seen in Tab 2. and Tab 3. for same thicknesses. Disadvantages for longer trajectory is pressure which rises approximately two times and of course higher usage of injected material.

\section{CONCLUSION}

Injection molding process of rubber can be optimized by the right choice of shape and thickness of runner. It depends on material family and economical aspects too. Shortening of time of vulcanization rapidly leads to safe energy. These analyses are basis for real process which is still in process. These two types of geometry are already made and prepared for injection molding process to compare these analyses with real process. It should be made and analysed more types of geometry with different thickness and it should be find the best one for various types of elastomeric compound in the further research.

\section{ACKNOWLEDGEMENTS}

This article is supported by the internal grant of TBU in Zlín No. IGA/10/FT/11/D funded from the resources of specific university research.

\section{REFERENCES}

Brnic, J. (2010). Properties Comparison of Two Constructural Steels: ASTM A709 and ASTM A505, DAAAM Symposium, 20-23rd October 2010, Zadar, Croatia, ISSN 1726-9679, ISBN 978-3-901509-73-5, Katalinic, B. (Ed.), pp. 0085-0086, DAAAM International Vienna, Vienna

Kazmer, L. (2007). Injection mold design engineering, Hanser Publishers, ISBN 978-3-446-41266-8, Munich, Germany

Kyas K.; Stanek M.; Manas M.; Manas D.; Krumal M. \& Cerny J. (2010). DAAAM, p. 1081, ISSN 1726-9679, ISBN 978-3901509-73-5, Zadar, Croatia

Kyas, K.; Stanek, M.; Manas, M.; Manas, D. \& Krumal, M. (2011). Simulation of rubber injection molding process, Chemicke listy, Volume 105, ISSN 0009-2770, pp. s354s356

Manas, D.; Stanek, M.; Manas, M.; Pata V. \& Javorik, J. (2009). Influence of Mechanical Properties on Wear of Heavily Stressed Rubber Parts, KGK - Kautschuk Gummi Kunststoffe, 62. Jahrgang, , ISSN 0948-3276, p.240-245

Rees, H. (2002). Mold engineering, Hanser Publishers, ISBN 3446-21659-6, Munich, Germany

Sanda, S.; Manas, M.; Manas, D.; Stanek, M. \& Senkerik, V. (2011). Gate effect on quality of injected part, Chemicke listy, Volume 105, ISSN 0009-2770, pp. s301-s303

Stanek, M.; Manas, M.; Manas, D. \& Sanda, S. (2009). Plastics Parts Design Supported by Reverse Engineering and Rapid Prototyping, Chemicke listy, Volume 103, ISSN 0009-2770, pp.91-95

Stanek, M.; Manas, M.; Manas, D. \& Sanda, S. (2009). Influence of Surface Roughness on Fluidity of Thermoplastics Materials, Chemicke listy, Volume 103, ISSN 0009-2770, p.91-95

Stanek, M.; Manas, M. \& Manas, D. (2009). Mold Cavity Roughness vs. Flow of Polymer, Novel Trends in Rheology III, AIP, ISSN 0094-243X, pp.75-85

Stanek, M.; Manas, M.; Drga, T. \& Manas, D. (2006) Polymer Fluidity Testing. 17th DAAAM, Vienna, Austria, p.395396, ISBN 3-901509-57-7

Stanek, M.; Manas, M.; Drga, T. \& Manas, D. (2006). Testing Injection Molds for Polymer Fluidity Evaluation, 17th DAAAM, Vienna, Austria, p.397-398,ISBN 3-901509-57-7 